\title{
Initial results of the chordal-cutting operation for ischemic mitral regurgitation
}

\author{
Michael A. Borger, MD, PhD, Patricia M. Murphy, MD, Asim Alam, MD, Shafie Fazel, MD, PhD, Manjula Maganti, MSc,
} Susan Armstrong, MSc, Vivek Rao, MD, PhD, and Tirone E. David, MD

Supplemental material is available online.
From the Division of Cardiovascular Surgery and Department of Anesthesia, Toronto General Hospital, University Health Network, and University of Toronto, Toronto, Ontario, Canada.

Read at the Eighty-sixth Annual Meeting of The American Association for Thoracic Surgery, Philadelphia, Pa, April 29-May 3, 2006.

Received for publication May 14, 2006; revisions received Jan 7, 2007; accepted for publication Jan 29, 2007.

Address for reprints: Michael A. Borger, MD, Division of Cardiovascular Surgery, Toronto General Hospital, 4N-451, 200 Elizabeth St, Toronto, Ontario, Canada M5G 2C4 (E-mail: michael.borger@med. uni-leipzig.de).

J Thorac Cardiovasc Surg 2007;133:1483-92 $0022-5223 / \$ 32.00$

Copyright $\odot 2007$ by The American Association for Thoracic Surgery

doi:10.1016/j.jtcvs.2007.01.064
Objective: Division of secondary chords (chordal cutting) has been proposed as a method for decreasing mitral valve leaflet tethering and mitral regurgitation in patients with ischemic mitral regurgitation. However, very little clinical data exist to date for this procedure.

Methods: We compared echocardiographic and clinical data in patients who underwent chordal-cutting mitral valve repair $(n=43)$ and those undergoing conventional mitral valve repair (control, $\mathrm{n}=49$ ) for ischemic mitral regurgitation.

Results: Patients who underwent chordal cutting had a higher prevalence of recent myocardial infarction, left main disease, diabetes, and peripheral vascular disease (all $P<.05$ ). Left ventricular ejection fraction was lower in the chordal-cutting group ( $33 \pm 2 \%$ vs $44 \pm 2 \%$ ) (mean \pm SE) and preoperative tent height was greater $(11.7 \pm 0.5$ vs $9.7 \pm 0.6 \mathrm{~mm}$; both $P<.01)$. In-hospital mortality was $10 \%$ in control patients and $9 \%$ in the chordal-cutting group $(P=.9)$. Other complication rates were similar for the two groups. The reduction in tent height before-to-after repair was similar in the two groups of patients, but those undergoing chordal cutting had a greater reductions in tent area $(53 \pm 3 \%$ vs $41 \pm 3 \% ; P=.01)$. The chordal-cutting group also had greater mobility of the anterior leaflet, as measured by a reduction in the distance between the free edge of the anterior mitral valve leaflet and the posterior left ventricular wall $(24 \pm 3 \%$ vs $11 \pm 4 \% ; P=.01)$. Control patients had more recurrent mitral regurgitation during 2 years of follow-up by univariate $(37 \%$ vs $15 \% ; P=.03)$ and multivariate analysis $(P=.03)$. Chordal cutting did not adversely affect postoperative left ventricular ejection fraction $(10 \%$ $\pm 5 \%$ relative increase in left ventricular ejection fraction vs $11 \% \pm 6 \%$ in the control group; $P=.9$ ).

Conclusion: Chordal cutting improves mitral valve leaflet mobility and reduces mitral regurgitation recurrence in patients with ischemic mitral regurgitation, without any obvious deleterious effects on left ventricular function.

I schemic mitral regurgitation (IMR) is always preceded by a myocardial infarction (MI) and is an important cause of cardiac morbidity and mortality after MI. IMR can be classified as acute or chronic, according to the time of presentation. Chronic IMR is a much more common clinical entity and is the focus of the current article.

Chronic IMR is defined as mitral regurgitation (MR) occurring greater than 1 week after MI with (1) one or more left ventricular (LV) segmental wall motion abnormalities, (2) significant coronary disease in the territory supplying the wall motion abnormality, and (3) structurally normal mitral valve (MV) leaflets and chordae tendineae. ${ }^{1}$ IMR is an important cause of congestive heart failure and is associated with worse long-term survival after MI. ${ }^{2-4}$ The prevalence of chronic IMR may be increasing with time, as a higher proportion of patients survive acute MI. It has been estimated that 1.2 to 2.8 million Americans currently have IMR. ${ }^{1,5}$ 

Abbreviations and Acronyms
$\mathrm{IMR}=$ ischemic mitral regurgitation
$\mathrm{LV}=$ left ventricular
MI = myocardial infarction
$\mathrm{MR}=$ mitral regurgitation
$\mathrm{MV}=$ mitral valve
TEE $=$ transesophageal echocardiography

The most common operation performed for chronic IMR is undersized mitral annuloplasty, as popularized by Bolling and colleagues. ${ }^{6,7}$ Although undersized mitral annuloplasty can be performed with acceptable rates of morbidity and mortality, several investigators have questioned its durability. McGee and colleagues ${ }^{8}$ demonstrated that recurrent MR (moderate-to-severe or severe) develops in $30 \%$ of patients 1 year after undersized annuloplasty, a finding that has been confirmed by others. ${ }^{9-11}$ In addition, undersized annuloplasty does not improve long-term survival in patients with chronic IMR. ${ }^{12}$ Such findings have led investigators to examine alternative methods of surgical treatment for IMR.

Recent advancements in the understanding of chronic IMR pathophysiology have led to new approaches in therapy. ${ }^{1,13}$ It is now widely accepted that the predominant cause of chronic IMR is apical displacement and tethering of the MV leaflets, preventing central coaptation during systole. Infarcted myocardium (predominantly in the posteroinferior territory) displaces the MV leaflets apically and outwardly and decreases ventricular force required to close the leaflets. ${ }^{14}$ The mitral annulus may dilate and therefore contribute to the regurgitation, but IMR can occur with a normal-sized annulus.

Such insights recently led to a novel surgical approach for chronic IMR. Messas, Levine, and colleagues ${ }^{15,16} \mathrm{dem}-$ onstrated that division of MV secondary chords (the "chordal-cutting" procedure) results in decreased leaflet tethering and decreased mitral insufficiency in a sheep model of IMR. Secondary chords attach to the belly of the MV leaflets and cause kinking of the anterior leaflet in patients with IMR, resulting in the "seagull sign" on echocardiography. ${ }^{1}$ The chordal-cutting procedure may relieve leaflet tethering, an important cause of recurrent mitral insufficiency after MV repair. ${ }^{11}$ The operation has been described in case reports, ${ }^{17,18}$ but clinical experience is very limited to date. We herein describe our early results in a group of patients undergoing the chordal-cutting operation and compare the clinical and echocardiographic outcomes with those of patients undergoing conventional MV repair for IMR.

\section{Patients and Methods}

Ethics approval for this study was granted by our institutional research ethics board. Our computerized database was examined to identify all patients undergoing MV repair for IMR from January
1, 1998, to December 31, 2005. We excluded patients undergoing MV replacement for IMR, as well as patients undergoing concomitant LV aneurysmectomy. Preoperative echocardiograms and operative reports were reviewed to confirm that the MV disease was ischemic in nature and to determine what type of surgical procedure was performed. Patients were divided into two groups according to operative technique: those undergoing conventional undersized mitral annuloplasty (control, $\mathrm{n}=49$ ) and those undergoing the chordal-cutting operation $(n=43)$.

Follow-up was obtained by telephone and mail questionnaire of patients or family members, or both, between January 1 and February 28, 2006. The first chordal-cutting operation was performed at our institution in May 2003. Some surgeons adopted this technique over the following 2 years whereas others continued to perform undersized mitral annuloplasty during the entire study period. Because the length of follow-up was longer in the control group, we truncated follow-up in all patients to 2 years postoperatively.

\section{Surgical Technique}

Indications for MV repair were symptoms of heart failure (New York Heart Association class II or greater) and moderate or more (ie, $2+$ or more) MR on preoperative echocardiography, although some patients with $1+$ MR also underwent MV repair. Intraoperative transesophageal echocardiography (TEE) was used to confirm the pathologic condition (ie, leaflet tethering) but not to determine whether or not MV repair was indicated.

A left atriotomy was performed posterior to the interatrial groove and the MV was thoroughly inspected to rule out nonischemic pathologic abnormalities. Interrupted 2-0 braided sutures without pledgets were placed along the posterior annulus from the medial to lateral fibrous trigones. A flexible incomplete annuloplasty band (Cosgrove-Edwards annuloplasty system; Edwards LifeSciences, Irvine, Calif) was inserted in both groups of patients. The annuloplasty band was moderately undersized in all patients and ranged from size 26 to 32, depending on the patient's body surface area.

In the chordal-cutting group, we divided secondary chords to the anterior leaflet, posterior leaflet, and the commissure that arose from the papillary muscle or muscles affected by the infarcted myocardium. Secondary chords arising from normal papillary muscles were not divided. The affected papillary muscle was identified by preoperative echocardiography or ventriculography or both. Secondary chordal cutting was performed before insertion of the annuloplasty band to optimize exposure. Secondary chords were carefully separated out from primary chords with a nerve hook, confirming their attachment to the belly of the leaflets rather than to the free edge. All secondary chords from the affected papillary muscle(s) that could be identified were divided.

\section{Echocardiography}

Transthoracic echocardiography was performed preoperatively, before discharge, and during the most recent follow-up in patients. MR grade was quantified as none or trivial (0), mild (1+), moderate $(2+)$, moderate-to-severe $(3+)$, or severe $(4+)$ on the basis of color jet area and shape, pulsed wave Doppler of pulmonary veins, and proximal isovelocity surface area. ${ }^{19} \mathrm{LV}$ ejection fraction was calculated by the modified Simpson and Quinones method. ${ }^{20}$ 
Intraoperative TEE was used to measure several variables before and after MV repair in a subset of patients. Measurements were performed by a single echocardiographer (P.M.), who was blinded to patient group assignment. All measurements were obtained via the mid-esophageal $120^{\circ}$ view, with the exception of tent height and area, which were obtained in the apical 4-chamber view. The measured variables were (1) mitral annulus diameter, (2) tent height (distance from the leaflet coaptation point to the mitral annulus), (3) tent area (area formed by the triangle between annular plane and the apex of the leaflet coaptation point into the ventricle during systole), and (4) anterior MV leaflet-posterior left ventricle (distance between the free edge of the anterior MV leaflet and the posterior LV wall as a measure of anterior leaflet mobility). Measurements were obtained during two different cardiac cycles and the average value was recorded. None of the patients had atrial fibrillation during measurement acquisition.

\section{Statistical Analysis}

Categorical variables are expressed as percentages and continuous variables are expressed as mean \pm standard deviation throughout the manuscript, with the exception of echocardiographic data, which are expressed as mean \pm standard error. All statistical analyses were performed with the SAS system (SAS version 8.1; SAS Institute, Inc, Cary, NC). Categorical variables were compared with $\chi^{2}$ or Fisher exact tests, and continuous variables were compared with unpaired $t$ or Wilcoxon tests. Stepwise multivariable logistic regression analysis was used to determine the independent predictors of recurrent MR. Survival and event-free survival were analyzed with the methods of Kaplan and Meier univariately and Cox regression multivariately.

\section{Results}

Preoperative characteristics for the two groups of patients are displayed in Table 1. Patients in the chordal-cutting group had significantly worse LV function than did control patients, as well as significantly larger LV diameters during systole. The chordal-cutting group was also more likely to have a history of MI within 30 days of surgery, left main coronary disease, diabetes mellitus, and peripheral vascular disease.

Intraoperative characteristics for the two groups of patients are displayed in Table 2. There were no significant differences for any of the listed variables, with the exception of a higher prevalence of left internal thoracic artery usage in the chordal-cutting group. Table 3 displays the early postoperative clinical outcomes for the two groups of patients. There were no significant differences for any of the variables listed with the exception of a higher prevalence of atrial fibrillation in the chordal-cutting group. In-hospital mortality was $10 \%$ in the isolated annuloplasty group and $9 \%$ in the chordal-cutting group $(P=.9)$.

\section{Echocardiographic Data}

Transthoracic echocardiography was performed in all patients preoperatively and in all surviving patients postoper-
TABLE 1. Preoperative characteristics for patients undergoing isolated mitral annuloplasty (control) or division of secondary chords plus annuloplasty (chordal cutting) for IMR

\begin{tabular}{|c|c|c|c|}
\hline Variable & $\begin{array}{l}\text { Control } \\
(n=49)\end{array}$ & $\begin{array}{l}\text { Chordal cutting } \\
\quad(n=43)\end{array}$ & $P$ value \\
\hline MR grade & & & .14 \\
\hline $1-2+$ & $29 \%$ & $43 \%$ & \\
\hline $3-4+$ & $71 \%$ & $57 \%$ & \\
\hline \multicolumn{4}{|l|}{ Direction of MR jet* } \\
\hline Central & $55 \%$ & $49 \%$ & .5 \\
\hline Eccentric & $20 \%$ & $28 \%$ & .4 \\
\hline Complex & $28 \%$ & $35 \%$ & .5 \\
\hline LV ejection fraction & $44 \% \pm 15 \%$ & $33 \% \pm 11 \%$ & $<.001$ \\
\hline LV diastolic diameter (mm) & $53 \pm 8$ & $56 \pm 10$ & .10 \\
\hline LV systolic diameter (mm) & $40 \pm 8$ & $45 \pm 11$ & .02 \\
\hline Age (y) & $63 \pm 8$ & $66 \pm 8$ & .09 \\
\hline Body surface area $\left(\mathrm{m}^{2}\right)$ & $1.9 \pm 0.2$ & $1.8 \pm 0.2$ & .12 \\
\hline Female sex & $29 \%$ & $38 \%$ & .3 \\
\hline Recent MI & $15 \%$ & $33 \%$ & .04 \\
\hline Congestive heart failure & $71 \%$ & $87 \%$ & .07 \\
\hline NYHA class IV & $47 \%$ & $64 \%$ & .08 \\
\hline Redo CABG & $10 \%$ & $5 \%$ & .3 \\
\hline Unstable angina & $16 \%$ & $24 \%$ & .2 \\
\hline Left main disease & $12 \%$ & $28 \%$ & .05 \\
\hline COPD & $2 \%$ & $0 \%$ & .6 \\
\hline Smoking history & $73 \%$ & $62 \%$ & .5 \\
\hline Urgent timing & $39 \%$ & $59 \%$ & .06 \\
\hline Preop stroke/TIA & $6 \%$ & $15 \%$ & .14 \\
\hline Hypertension & $67 \%$ & $69 \%$ & .9 \\
\hline Hyperlipidemia & $63 \%$ & $72 \%$ & .4 \\
\hline Renal failure & $4 \%$ & $3 \%$ & .8 \\
\hline Diabetes mellitus & $31 \%$ & $51 \%$ & .04 \\
\hline $\begin{array}{l}\text { Peripheral vascular } \\
\text { disease }\end{array}$ & $12 \%$ & $33 \%$ & .01 \\
\hline Aortic valve disease & $6 \%$ & $9 \%$ & .4 \\
\hline Tricuspid valve diseae & $8 \%$ & $8 \%$ & .9 \\
\hline
\end{tabular}

Continuous variables are expressed as mean \pm standard deviation. $I M R$, Ischemic mitral regurgitation; $M R$, mitral regurgitation; $L V$, left ventricle; $M I$, myocardial infarction; NYHA, New York Heart Association classification; $C A B G$, coronary artery bypass grafting; $C O P D$, chronic obstructive pulmonary disease; $T I A$, transient ischemic attack. *Eccentric mitral regurgitation jet refers to posterolateral or anterolateral direction; complex jet refers to an eccentric jet or multiple jets.

atively. The prevalence of preoperative central, eccentric, and complex MR jets is displayed in Table 1.

Detailed measurements were obtained from intraoperative TEE in $82 \%$ of patients $(n=75)$. The intraoperative TEE digital tape was irretrievable in 12 patients or had inadequate images in 3 patients, whereas 2 patients had a contraindication to TEE examination. As can be seen in Table 4, the tent height (distance between the coaptation point of the MV leaflets and the mitral annulus) was significantly greater in the chordal-cutting group before MV 
TABLE 2. Intraoperative characteristics for the two groups of patients

\begin{tabular}{lccc}
\hline Variable & $\begin{array}{c}\text { Control } \\
(\mathbf{n}=\mathbf{4 9})\end{array}$ & $\begin{array}{c}\text { Chordal cutting } \\
(\mathbf{n}=\mathbf{4 3})\end{array}$ & $\boldsymbol{P}$ value \\
\hline Size of MV band & & & .4 \\
$\quad 26$ & $10 \%$ & $9 \%$ & \\
28 & $31 \%$ & $40 \%$ & \\
30 & $45 \%$ & $40 \%$ & \\
32 & $14 \%$ & $11 \%$ & \\
Coronary bypass grafting & $92 \%$ & $92 \%$ & .9 \\
Use of LITA & $43 \%$ & $64 \%$ & .04 \\
Aortic valve surgery & & & .4 \\
$\quad$ Replacement & $6 \%$ & $7 \%$ & \\
$\quad$ Repair & $0 \%$ & $2 \%$ & \\
Tricuspid valve surgery & & & .6 \\
$\quad$ Replacement & $6 \%$ & $0 \%$ & \\
$\quad$ Repair & $2 \%$ & $8 \%$ & \\
Maze procedure & $2 \%$ & $2 \%$ & .9 \\
Crossclamp time (min) & $93 \pm 23$ & $107 \pm 25$ & .5 \\
CPB time (min) & $119 \pm 33$ & $131 \pm 28$ & .3 \\
\hline
\end{tabular}

Continuous variables are expressed as mean \pm standard deviation. $M V$, Mitral valve; $L I T A$, left internal thoracic artery; $C P B$, cardiopulmonary bypass.

repair. Chordal cutting resulted in a significantly increased reduction in the tent area after MV repair (the area between the mitral annulus and the coaptation point of the leaflets), as well as increased reduction in the distance between the free edge of the anterior MV leaflet and the posterior LV wall.

The change in MR on transthoracic echocardiography from before to after the operation in patients who survived the perioperative period is displayed in Figure 1. The average grade of MR was similar between groups preopera-

TABLE 3. Postoperative outcomes for the two groups of patients

\begin{tabular}{lccc}
\hline Variable & $\begin{array}{c}\text { Control } \\
(\mathbf{n}=\mathbf{4 9})\end{array}$ & $\begin{array}{c}\text { Chordal cutting } \\
(\mathbf{n}=\mathbf{4 3})\end{array}$ & $\boldsymbol{P}$ value \\
\hline Myocardial infarction & $2 \%$ & $0 \%$ & .6 \\
Low cardiac output syndrome & $8 \%$ & $15 \%$ & .3 \\
Stroke & $2 \%$ & $5 \%$ & .4 \\
Reoperation for bleeding & $6 \%$ & $5 \%$ & .9 \\
Renal failure & $2 \%$ & $5 \%$ & .4 \\
Atrial fibrillation & $22 \%$ & $44 \%$ & .03 \\
Pacemaker & $16 \%$ & $23 \%$ & .4 \\
Mortality & $10 \%$ & $9 \%$ & .9 \\
Ventilation time (h) & $37 \pm 80$ & $61 \pm 164$ & .1 \\
ICU stay (d) & $4.6 \pm 5.5$ & $5.0 \pm 7.7$ & .3 \\
Hospital stay (d) & $11 \pm 6$ & $12 \pm 9$ & .5
\end{tabular}

Continuous variables are expressed as mean \pm standard deviation. ICU, Intensive care unit.
TABLE 4. Intraoperative transesophageal echocardiographic measurements

\begin{tabular}{lccc}
\hline Variable & $\begin{array}{c}\text { Control } \\
(\mathbf{n}=\mathbf{3 9})\end{array}$ & $\begin{array}{c}\text { Chordal cutting } \\
(\mathbf{n}=\mathbf{3 6})\end{array}$ & $\boldsymbol{P}$ value \\
\hline Mitral annular diameter (mm) & $34 \pm 1$ & $35 \pm 1$ & .3 \\
Tent area $\left(\mathrm{cm}^{2}\right)$ & $2.5 \pm 0.2$ & $2.9 \pm 0.2$ & .14 \\
AMVL-posterior LV (mm) & $24 \pm 9$ & $21 \pm 6$ & .2 \\
$\begin{array}{l}\text { Prerepair to postrepair } \\
\quad \text { reduction }\end{array}$ & & & \\
$\quad$ Mitral annulus & $28 \% \pm 3 \%$ & $33 \% \pm 2 \%$ & .2 \\
$\quad$ Tent height & $20 \% \pm 3 \%$ & $24 \% \pm 4 \%$ & .4 \\
$\quad$ Tent area & $41 \% \pm 3 \%$ & $53 \% \pm 3 \%$ & .01 \\
$\quad$ AMVL-posterior LV & $11 \% \pm 4 \%$ & $24 \% \pm 3 \%$ & .01 \\
\hline
\end{tabular}

Continuous variables are expressed as mean \pm standard error. $A M V L$, Anterior mitral valve leaflet; $L V$, left ventricle.

tively, but it was significantly lower in the chordal-cutting group postoperatively.

The most recent echocardiogram (truncated at 2 years postoperatively in the control group) revealed moderate or more MR (ie, $2+$ or greater) in $15 \%$ of surviving patients having the chordal-cutting procedure and $37 \%$ of control patients $(P=.04)$. Logistic regression analysis revealed that the type of operation was the only independent predictor of recurrent MR (odds ratio 3.9 for undersized annuloplasty; $P=.03$ ).

As noted earlier, LV function was significantly worse in the chordal-cutting group preoperatively. The change in LV ejection fraction from the preoperative to the follow-up period was similar in the two groups of patients: $10 \% \pm$ $28 \%$ relative (not absolute) increase in the chordal-cutting group versus $11 \% \pm 39 \%$ in the control group $(P=.9)$.

\section{Clinical Outcomes During Follow-up}

Survival 2 years postoperatively was $82 \% \pm 6 \%$ in the control group and $79 \% \pm 9 \%$ in the chordal-cutting group $(P=.8$, Figure E1). The causes of death during follow-up in the chordal-cutting group were complications of perioperative stroke in 1 patient and hemolysis and end-stage renal failure in 1 patient. In the control group, the causes of death during follow-up were congestive heart failure, renal failure, and thoracic aneurysm surgery (1 patient each). Cox regression failed to reveal any independent predictors of long-term survival.

Figure E2 displays the event-free survival for the two groups, defined as freedom from death, recurrent moderate or more MR $(2+$ or greater), reoperation, thromboembolism, hemolysis, major hemorrhage, or endocarditis. Thromboembolism occurred in 1 patient in each group during follow-up, hemolysis occurred in 1 patient in each group, endocarditis occurred in 1 control patient, and major hemorrhage did not occur in any patient. A total of 5 patients in the control group underwent reoperative MV replacement in 


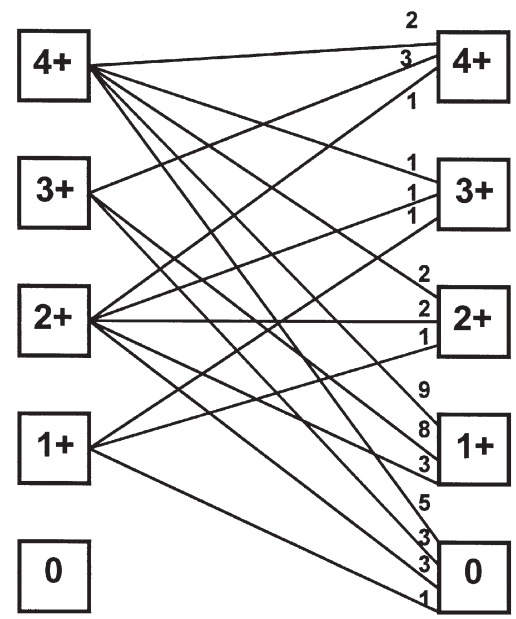

Pre-op

$(3.0 \pm 0.9)$
Post-op

(1.4 \pm 1.3$)$

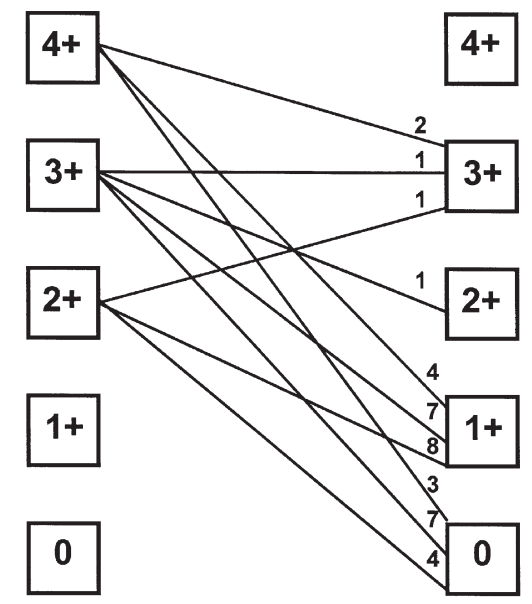

Pre-op

$(2.8 \pm 0.8)$
Figure 1. Grade of MR preoperatively and during follow-up in the control group (left) and the chordal-cutting group (right). Both groups showed a significant reduction in the grade of MR from before to after surgery $(P<$ .001). Preoperative MR grade was similar between groups, but postoperative MR grade was lower in the chordalcutting group $(P=.04)$. MR, mitral regurgitation. the first 2 years postoperatively: 3 patients for recurrent MR, 1 for hemolysis and recurrent MR, and 1 for endocarditis. In contrast, none of the patients in the chordal-cutting group underwent reoperation. However, recurrent MR developed 6 months postoperatively as a result of dehiscence of the annuloplasty ring in 1 patient in the chordal-cutting group. The patient had severe hemolysis and renal failure but was turned down for reoperation because of multiple comorbidities. The patient died 11 months postoperatively.

Event-free survival was $52 \% \pm 7 \%$ in the control group and $70 \% \pm 9 \%$ in the chordal-cutting group 2 years postoperatively $(P=.2$, Figure E2). Cox regression revealed that eccentric MR was the only independent predictor of decreased event-free survival (hazard ratio $3.4 ; P=.02$ ).

\section{Discussion}

IMR is a consequence of MI. The hallmark of IMR is mitral insufficiency in the face of structurally normal MV leaflets and chords. The predominant cause of IMR is apical displacement and tethering of the MV leaflets, with subsequent decreased coaptation. Infarcted myocardium results in displacement of the affected papillary muscle during systole, as well as decreased closing forces on the leaflets. ${ }^{13,14}$ Mitral annular dilation may also occur and can lead to increased insufficiency, but annular dilation is not essential for the development of IMR.

MV repair results in better survival than MV replacement in patients with IMR, except in high-risk patients, in whom survival is similar for the two techniques. ${ }^{21,22}$ The most commonly performed surgical procedure for IMR is isolated undersized annuloplasty. Isolated annuloplasty is reproducible and can be performed with acceptable rates of morbidity and mortality, even in high-risk patients. ${ }^{6,7}$ However, undersized annuloplasty does not significantly im- prove long-term survival when compared with medical management. ${ }^{12}$ Several investigators have described a high rate of MR recurrence, approximately 30\%, after undersized isolated annuloplasty for IMR. ${ }^{8-11}$ Such findings have led investigators to examine a host of other surgical options, including the edge-to-edge (Alfieri) repair, infarct plication, papillary muscle imbrication, papillary muscle "sling," surgical relocation of the posteromedial papillary muscle, and posterior MV restoration. ${ }^{1}$ The amount of clinical experience with each of these techniques is very limited.

Messas, Levine, and associates ${ }^{15,16}$ proposed division of the secondary chords as a method of improving leaflet mobility and decreasing leaflet tethering for chronic IMR. Secondary chords result in kinking of the anterior MV leaflet in chronic IMR but are not required to prevent leaflet prolapse. Messas and colleagues demonstrated that dividing secondary chords in a sheep model of acute ${ }^{15}$ and chronic ${ }^{16}$ IMR resulted in improved leaflet coaptation and reduced $\mathrm{MR}$, without leaflet prolapse or decline in LV ejection fraction. The chordal-cutting operation is intended to prevent persistent leaflet tethering after MV repair, an important cause of recurrent IMR. ${ }^{11}$ It has been described in a few case reports in humans, ${ }^{17,18}$ but clinical experience is very limited.

We started performing the chordal-cutting operation in 2003 and have been performing this procedure in an increasing number of patients over time. The current article describes our early results with this group of patients and compares them with a group that underwent isolated undersized annuloplasty. The chordal-cutting group had an increased prevalence of several preoperative risk factors, including worse LV function, than the control group. This finding probably reflects our increased comfort level with 
the chordal-cutting procedure and our willingness to perform this operation in higher-risk patients.

We used a flexible, incomplete annuloplasty band for all patients in the current study. Several articles in the literature have discussed the optimal annuloplasty device for patients with chronic IMR, with conflicting results. Although many surgeons prefer a complete ring, ${ }^{23}$ we use an incomplete band because we do not believe dilation of the intertrigonal distance plays a major role in the pathogenesis of IMR. ${ }^{24} \mathrm{In}$ the current study, the mitral annulus measured $3.4 \pm 0.1$ $\mathrm{mm}$ in all patients (Table 4), which is within the range of normal values. ${ }^{25}$ Although it can be argued that our results may have improved with the use of a complete, rigid ring, it is important to stress that both groups of patients received the same annuloplasty device and therefore a comparison of the two groups should yield a valid estimate of the effect of chordal cutting.

The predominant concern for the chordal-cutting operation has been possible deleterious effects on LV function. Rodriguez and colleagues ${ }^{26}$ used an acute IMR sheep model to demonstrate that division of the anterior leaflet secondary chords results in decreased LV function. These investigators demonstrated decreases in end-systolic elastance and preload recruitable stroke work, as well as increased transmural strain and altered LV geometry, after anterior leaflet chordal cutting in acutely ischemic sheep. These same investigators also demonstrated that chordal cutting had no beneficial effect on mitral insufficiency in an acute sheep model of IMR. ${ }^{27}$ These findings are in contrast to the studies by Messas and associates, ${ }^{16}$ which demonstrated reduced MR and no decrease in LV ejection fraction at a mean period of 33 weeks after chordal cutting in a chronic ischemia model. A recent publication by the same investigators demonstrated preservation of LV volumes, ejection fraction, systolic ventricular elastance, preload-recruitable stroke work, and LV rate of pressure rise after secondary chordal cutting. ${ }^{28}$ One explanation for these discrepant findings is that acute ischemia models are more likely to show decreases in LV function because the papillary muscles and surrounding myocardium are normal. In contrast, models of chronic ischemia are more representative of the clinical situation in which papillary muscles and surrounding myocardium are infarcted and scarred. Cutting secondary chords that arise only from infarcted myocardium, as done in the current study, may not be as deleterious as cutting chords from normal, healthy myocardium.

We failed to demonstrate any significant echocardiographic decrease in LV function after chordal cutting in the current study, a finding that can be supported by several lines of evidence. First, there was no significant increase in inotrope usage or low cardiac output syndrome in the chordalcutting group, despite the fact that this group had worse LV function than control patients. Second, operative mortality was similar for the two groups, despite a higher prevalence of several risk factors in the chordal-cutting group. Our perioperative mortality rate for the chordal-cutting group (9\%) was similar to that achieved in large series of MV repair for IMR (approximately 10\%). ${ }^{21,29}$ Third, division of secondary chords has been performed for more than 20 years during MV repair for myxomatous disease (during sliding annuloplasty and chordal transfer procedures) with excellent long-term results and no obvious deleterious effects on patient survival or symptoms. ${ }^{30}$ We therefore believe that chordal cutting does not adversely affect LV function in patients with chronic IMR.

In the current study, recurrent moderate or more MR was observed in $37 \%$ of the isolated annuloplasty group. Other investigators have achieved better results after MV repair for IMR, particularly Braun and associates. ${ }^{31}$ These investigators had an $8 \%$ rate of MR recurrence 18 months postoperatively. One possible explanation for their better results is that these investigators used a complete, rigid ring with more aggressive undersizing. However, we should once again stress that both groups of patients in our study received the same size and type of annuloplasty device and therefore the incremental effect of chordal cutting should be valid. Although the MR recurrence rate in our control group is relatively high, it is well within the quoted range in the literature..$^{8-11}$

The mechanism of recurrent MR after isolated annuloplasty is likely related to persistent leaflet tethering. ${ }^{11} \mathrm{Di}$ vision of secondary chords was associated with a decreased recurrence rate of MR in the current study by univariate and multivariate analysis. The decreased recurrence rate was particularly noteworthy given that patients in the chordalcutting group had increased MV leaflet tenting preoperatively (Tables 1 and 4), a risk factor for recurrent MR. ${ }^{11,32}$

Chordal cutting may reduce MR by increasing leaflet mobility and decreasing leaflet tethering. ${ }^{15,16}$ In the current study, patients subjected to chordal cutting had decreased MV tent height and tent area after MV repair. They also had a decreased distance between leaflet coaptation and the posterior LV wall, suggestive of increased mobility of the anterior leaflet. Other investigators have demonstrated increased anterior leaflet mobility and concave curvature after division of the secondary chords. ${ }^{33,34}$ Despite our positive findings, recurrent MR still occurred in 15\% of the chordalcutting group. We can infer that chordal cutting represents an incremental improvement over isolated annuloplasty for surgical treatment of IMR, but it is not the final answer for this vexing clinical problem.

\section{Study Limitations}

The main limitation of the current study is its retrospective and nonrandomized design. A randomized clinical trial would be the most appropriate method of comparing 
chordal cutting with undersized annuloplasty for IMR. However, MV repair for IMR is an uncommon surgical procedure, despite the large number of patients with this disorder, and therefore a randomized trial is unlikely to be performed in the near future. Since chordal cutting is currently being performed in several centers around the world, the current study represents the best available data on this new procedure.

Another limitation of the current study is our method of assessing postoperative LV function. We used transthoracic echocardiography, which is load-dependent. Although all clinical tests of LV function are load-dependent to a certain extent, rest and exercise nuclear angiography may be a better measure of LV function and may be preferable for future studies.

Another possible limitation is that patients in the chordalcutting group had a higher prevalence of recent MI and a higher percentage of left internal thoracic artery usage, which may have led to better reverse remodeling and less MR postoperatively. However, type of operation performed was the only independent predictor of recurrent MR in our multivariable analysis, even after adjusting for preoperative MI and left internal thoracic artery usage.

The final limitation of our study is the relatively short period of follow-up. It is possible that chordal cutting is not as durable as undersized annuloplasty for IMR, but only time will tell. However, the current study included up to 2 years of follow-up, and most cases of MR recur within the first year after MV repair for IMR. ${ }^{8}$

\section{Conclusions}

We compared clinical and echocardiographic outcomes in patients undergoing the chordal-cutting procedure with those undergoing undersized annuloplasty. Although the chordal-cutting group had an increased risk profile, including worse LV function and more mitral leaflet tenting, perioperative outcomes were similar. Chordal cutting resulted in decreased leaflet tenting, increased leaflet mobility, and decreased recurrence of MR during follow-up. We can conclude that chordal cutting represents a safe, incremental improvement over undersized annuloplasty for the treatment of IMR. However, further refinements are probably necessary before we can claim success in the surgical treatment of this difficult clinical problem.

We acknowledge the help of Joan Ivanov, $\mathrm{PhD}$, with statistical analyses.

\section{References}

1. Borger MA, Alam A, Murphy PM, Doenst T, David TE. Ischemic mitral regurgitation: repair, replace or revisit? Ann Thorac Surg. 2006; 81:1153-61.

2. Lamas GA, Mitchell GF, Flaker GC, Smith SC Jr, Gersh BJ, Basta L, et al. Clinical significance of mitral regurgitation after acute myocar- dial infarction. Survival and Ventricular Enlargement Investigators. Circulation. 1997;96:827-33.

3. Grigione F, Enriquez-Sarano M, Zehr KJ, Bailey KR, Tajik AJ. Ischemic mitral regurgitation: long-term outcome and prognostic implications with quantitative Doppler assessment. Circulation. 2001; 103:1759-64.

4. Trichon BH, Felker GM, Shaw LK, Cabell CH, O'Connor CM. Relation of frequency and severity of mitral regurgitation to survival among patients with left ventricular systolic dysfunction and heart failure. Am J Cardiol. 2003;91:538-43

5. Gorman RC, Gorman JH III, Edmunds LH Jr. Ischemic mitral regurgitation. In: Cohn LH, Edmunds LH Jr, editors. Cardiac surgery in the adult. New York: McGraw-Hill; 2003. p. 751-69.

6. Bolling SF, Pagani FD, Deeb GM, Bach DS. Intermediate-term outcome of mitral reconstruction in cardiomyopathy. $J$ Thorac Cardiovasc Surg. 1998;115:381-6.

7. Bolling SF, Deeb GM, Bach DS. Mitral valve reconstruction in elderly, ischemic patients. Chest. 1996;109:35-40.

8. McGee EC, Gillinov AM, Blackstone EH, Rajeswaran J, Cohen G, Najam F, et al. Recurrent mitral regurgitation after annuloplasty for functional ischemic mitral regurgitation. J Thorac Cardiovasc Surg. 2004;128:916-24.

9. Tahta SA, Oury JH, Maxwell JM, Hiro SP, Duran CM. Outcome after mitral valve repair for functional ischemic mitral regurgitation. J Heart Valve Dis. 2002;11:11-8.

10. Serri K, Bouchard D, Demers P, Coutu M, Pellerin M, Carrier M, et al Is a good perioperative echocardiographic result predictive of durability in ischemic mitral valve repair? J Thorac Cardiovasc Surg. 2006; 131:565-73.

11. Zhu F, Otsuji Y, Yotsumoto G, Yuasa T, Ueno T, Yu B, et al. Mechanism of persistent ischemic mitral regurgitation after annuloplasty: importance of augmented posterior mitral leaflet tethering. Circulation. 2005(9 Suppl);112:1396-401.

12. Wu AH, Aaronson KD, Bolling SF, Pagani FD, Welch K, Koelling TM. Impact of mitral valve annuloplasty on mortality risk in patients with mitral regurgitation and left ventricular systolic function. $J \mathrm{Am}$ Coll Cardiol. 2005;45:381-7.

13. Levine RA, Schwammenthal E. Ischemic mitral regurgitation on the threshold of a solution: from paradoxes to unifying concepts. Circulation. 2005;112:745-58.

14. Levine RA. Dynamic mitral regurgitation: more than meets the eye. N Engl J Med. 2004;351:1681-4.

15. Messas E, Guerro JL, Handschumacher MD, Conrad C, Chow CM, Sullivan S, et al. Chordal cutting. A new therapeutic approach for ischemic mitral regurgitation. Circulation. 2001:104:1958-63.

16. Messas E, Pouzet B, Touchot B, Guerrero JL, Vlahakes GJ, Desnos M, et al. Efficacy of chordal cutting to relieve chronic persistent ischemic mitral regurgitation. Circulation. 2003(Suppl 1);108:II111-5.

17. Yamamoto H, Iguro Y, Sakata R, Arata K, Yotsumoto G. Effectively treating ischemic mitral regurgitation with chordal cutting in combination with ring annuloplasty and left ventricular reshaping approach. J Thorac Cardiovasc Surg. 2005;130:589-90.

18. Fayad G, Modine T, Le Tourneau T, Al-Ruzzeh S, Ennezat PV, Decoene $\mathrm{C}$, et al. Chordal cutting technique through aortotomy: a new approach to treat chronic ischemic mitral regurgitation. $J$ Thorac Cardiovasc Surg. 2005;129:1173-4.

19. Zoghbi W, Enriquez-Sarano M, Foster E, Grayburn PA, Kraft CD, Levine RA, et al. Recommendations for evaluation of the severity of native valvular regurgitation with two-dimensional and Doppler echocardiography. J Am Soc Echocardiogr. 2003;16:777-802.

20. Dias BF, Yu EH, Sloggett CE, Iwanochko RM, Rakowski H, Siu SC. Contrast-enhanced quantitation of left ventricular ejection fraction: what is the best method? J Am Soc Echocardiogr. 2001;14:1183-90.

21. Gillinov AM, Wierup PN, Blackstone EH, Bishay ES, Cosgrove DM, White $\mathrm{J}$, et al. Is repair preferable for ischemic mitral regurgitation? J Thorac Cardiovasc Surg. 2001;122:1125-41.

22. Miller DC. Ischemic mitral regurgitation redux-to repair or to replace? J Thorac Cardiovasc Surg. 2001;122:1059-62.

23. Gorman JH, Gorman RC, Jackson BM, Enomoto Y, St John-Sutton MG, Edmunds LH. Annuloplasty ring selection for chronic ischemic 
mitral regurgitation: lessons from the ovine model. Ann Thorac Surg. 2003;76:1556-63.

24. Otsuji Y, Kumanohoso T, Yoshifuku S, Matsukida K, Koriyama C, Kisanuki A, et al. Isolated annular dilation does not usually cause important functional mitral regurgitation: comparison between patients with lone atrial fibrillation and those with idiopathic or ischemic cardiomyopathy. J Am Coll Cardiol. 2002;39:1651-6.

25. Savage RM, Aronson S, editors. Intraoperative transesophageal echocardiography. Philadelphia: Lippincott Williams \& Wilkins; 2005. Appendix A-5.

26. Rodriguez F, Langer F, Harrington KB, Tibayan FA, Zasio MK, Cheng A, et al. Importance of mitral valve second-order chordae for left ventricular geometry, wall thickening mechanics, and global systolic function. Circulation. 2004(11 Suppl 1);110:II115-22.

27. Rodriguez F, Langer F, Harrington KB, Tibayan FA, Zasio MK, Liang $\mathrm{D}$, et al. Cutting second-order chords does not prevent acute ischemic mitral regurgitation. Circulation. 2004(11 Suppl 1);110:II91-7.

28. Messas E, Yosefy C, Chaput M, Guerrero JL, Sullivan S, Menasche P, et al. Chordal cutting does not adversely affect left ventricle contractile function. Circulation. 2006;114:I524-8.

29. Grossi EA, Goldberg JD, LaPietra A, Ye X, Zakow P, Sussman M, et al. Ischemic mitral valve reconstruction and replacement: comparison of long-term survival and complications. J Thorac Cardiovasc Surg. 2001;122:1107-24.

30. David TE, Ivanov J, Armstrong S, Rakowski R. Late outcomes of mitral valve repair for floppy valves: implications for asymptomatic patients. J Thorac Cardiovasc Surg. 2003;125:1143-52.

31. Braun J, Bax JJ, Versteegh MI, Voigt PG, Holman ER, Klautz RJ, et al. Preoperative left ventricular dimensions predict reverse remodeling following restrictive mitral annuloplasty in ischemic mitral regurgitation. Eur J Cardiothorac Surg. 2005;27:847-53.

32. Calafiore AM, Gallina S, DiMauro M, Gaeta F, Iaco AL, D'Alessandro $\mathrm{S}$, et al. Mitral valve procedure in dilated cardiomyopathy: repair or replacement? Ann Thorac Surg. 2001;71:1146-53.

33. Goetz WA, Lim HS, Pekar F, Saber HA, Weber PA, Lansac E, et al. Anterior mitral leaflet mobility is limited by the basal stay chords. Circulation. 2003;107:2969-74.

34. Rodriguez F, Langer F, Harrington KB, Tibayan FA, Zasio MK, Liang D, et al. Effect of cutting second-order chordae on in-vivo anterior mitral leaflet compound curvature. J Heart Valve Dis. 2005; 14:592-601.

\section{Discussion}

Dr D. Craig Miller (Stanford, Calif). Thank you, Dr Borger. That was a nice presentation. I don't want anyone in this room to run home and try this, however. Despite how great it looks on the surface, it looks too good to be true and probably is too good to be true.

Let me reframe the controversy for the audience. Robert Levine's MGH group has shown in acute and chronic sheep models of IMR that if you cut the second-order chords there is more leaflet area for coaptation and the valve is more competent. My concern has always been what cost do you pay in terms of ventricular systolic function when you cut the second-order chordae? Indeed, it is ironic that the senior author on this paper is the very one and same Tirone E. David who first convincingly demonstrated in a canine experimental preparation 23 years ago that cutting the chordae tendineae was bad for left ventricular systolic function. Further, these are sick ventricles. To paraphrase the Gorman brothers: IMR is not a valvular disease, it's a ventricular disease, and these are sick ventricles crying out for help. If we impair their LV contractile performance more, we actually may be harming patients even if there is less postoperative recurrent IMR.

Congratulations for proving in the first sizable clinical series that cutting second-order chordae is feasible and safe with no apparent early side effects. I remain unconvinced, however, that the putative mechanism responsible for less recurrent MR was actually due to what you did. I also am skeptical that you actually did not impair left ventricular systolic function by cutting the chords.

Why am I unconvinced? First, you do not have the proper concurrent control group -- similar patients with IMR undergoing CABG alone -- but none of us do. A prospective controlled trial where one-half of your IMR patients was randomized to chordal division would be ideal, but we do not live in a utopia. More practically speaking, you have not analyzed all the intra-operative and postoperative echo data available to you, which is where you have let us and yourselves down.

You showed us intraoperative TEE data for just the first 20 patients in each group. Why didn't you analyze the echo data for all 92 patients? Further, you focused exclusively on type III-b leaflet motion (restricted systolic leaflet closure). IMR is often a combination of septal-lateral (S-L) annular dilatation (type I or normal leaflet motion with IMLC) and type III-b leaflet motion. You didn't even tell us what kind of moderate IMR leaks you were treating. Were these eccentric complex MR jets (type III-B) or central straight back jets (type I), or both mechanisms, as we frequently see?

As an editorial comment, I think you have used the completely wrong type of ring for these IMR patients. A Cosgrove band is great for prolapse, but I think most of us now believe IMR is best treated by a complete, very rigid ring which by design disproportionately downsizes the AP or S-L annular axis.

Let's get back to the echo information. I was disappointed that you presented quantitative intraoperative TEE data for only 20 patients in each group. Indeed, you could not even prove statistically that cutting the second-order chordae reduced tenting area or height compared to the more conventional ring only group based on these numbers. Maybe analysis of larger numbers of patients would have allowed you to substantiate your the conclusion and prove that the reduced incidence of postoperative IMR was due to less apical tethering, a direct effect of cutting the second-order chordae. Further, for the 2 year postoperative transthoracic echocardiograms you don't give us any information aside from how many patients had moderate or worse recurrent IMR. What about mitral S-L annular dimension, tenting area, tenting height and all the LV dimensions and geometry for all survivors in both groups, and specifically for those with recurrent IMR? Was there more salutary reverse LV remodeling over time in the chordal-cutting group? I applaud you for demonstrating a major reduction in postoperative residual/recurrent IMR in the chordal division group, but we need to know why this happened on a mechanistic basis. I'm just not sure that cutting the second-order chordae truly explains these favorable results. Many things were changing over time, the patient cohorts were dissimilar, and these two technical approaches were applied sequentially and not concurrently.

Concerning LV systolic function, as you and I have discussed earlier, the audience should be circumspect in that you did perform any rest and exercise echo or radionuclear stress testing to assess LV contractile reserve. Just looking at changes in resting echo EF is not very persuasive.

In the event-free survival curves which clearly favored the chordal-cutting technique, perhaps you may have been a little bit misleading. You excluded recurrent IMR as part of this composite clinical end-point. There was one patient in the chordal-cutting group who had severe recurrent MR but was deemed inoperable and therefore not reoperated on. This important complication is missing from these curves. Better yet, if you would have included all events, including 
recurrent MR, I think you have enough adverse events in a large enough population that these data could have been subjected to what the Toronto group has regularly done in their clinical research efforts, that is, test your hypothesis using a rigorous multivariable Cox model with bootstrapping, ideally including propensity score analysis (if you had enough patients to unbalance the numbers in order to balance the risk of adverse outcome). Some of the independent variables to be entered would include all the clinical descriptors, operative year, surgeon identifier, chordal-cutting technique or not, annuloplasty band size, and interval between last MI to operation. This type of comprehensive statistical approach is the only robust way to demonstrate from your retrospective data whether or not dividing the second-order chords is more effective than your conventional repair method. Let us not forget that patient selection biases and surgeon bias are ubiquitous!

I thank you, Mike, and your colleagues for this important work and demonstrating it is safe and feasible to cut the second-order chordae during mitral valve repair for patients with IMR. I only wish all the data had been analyzed and the statistical approach had been more rigorous.

Dr. Borger: Thank you, Dr. Miller. Trying to defend a paper on ischemic mitral regurgitation to you is a little bit like trying to defend a paper on the theory of relativity to Einstein. But I will try.

First of all, your comments about how our philosophy has changed from preaching that we have to retain chords to now saying that we can sacrifice them, there is a bit of a subtle difference there. The original studies that said that we should retain continuity between the annulus and the papillary muscles when you replace the mitral valve, they did not make a distinction between primary and secondary chords. What we are proposing now is cutting the secondary chords only. The primary chords remain intact and therefore there is continuity of the papillary muscle-annular mechanism.

Why did we not obtain detailed intraoperative echo data on all of the patients? My only response is that these measurements are extremely time-consuming to perform. All of these measurements were obtained during off-line analysis of two different cardiac cycles, which takes a lot of time. In addition, we felt that the more important clinical outcome was recurrent mitral regurgitation on postoperative transthoracic echo rather than intraoperative TEE measurments. But you've raised a valid point and I will have to go back and queue up those tapes and get some more data on the remaining patients.

Regarding your question on the mechanism of the mitral regurgitation, it was a typical ischemic MR leak with a combined eccentric jet and central component in the majority of patients. It is not our observation that ischemic MR is due mostly to annular dilatation. We believe that annular dilatation plays a relatively minor role in ischemic MR. When you look at our data, the average mitral annulus diameter in both groups was only $3.4 \mathrm{~cm}$, which is at the upper end of normal. The data on the type of regurgitant jet is currently missing from the paper, but I do have it and I will insert it.

It has been our institutional philosophy for many years that we use a partial incomplete flexible ring for ischemic MR. I am very familiar with the literature for ischemic mitral regurgitation, I know there are a lot of proponents of a complete rigid ring. However, I do not believe it has been conclusively shown that a complete rigid ring is absolutely required. I think that it is still in the stage of equipoise, and hopefully over time somebody will be able to definitively determine the optimal ring type. For now we are using partial incomplete rings, but a couple of years from now we may be switching to a complete rigid ring. .

As far as left ventricular function goes, we used postoperative transthoracic echocardiography and this is probably not the best method. Radionuclide angiography is probably a better method. However, these tests are not part of our standard postoperative clinical follow-up evaluation. Regardless, we feel there is a lot of evidence suggesting that we did not adversely affected left ventricular function. Despite the chordal-cutting group having a $10 \%$ lower ejection fraction, and that was an absolute $10 \%$ difference and not a relative $10 \%$, these patients had no increase rate of inotrope usage, low cardiac output syndrome, and or mortality when compared to the undersized annuloplasty group. So we feel comfortable with this operation and we do not think that it results in any obvious decrement in left ventricular function.

And then finally to address your point about our definition of event-free survival. We used a definition based on the currently accepted norms for valve surgery reporting, and those norms usually do not include recurrent MR without reoperation. Certainly we can add recurrent MR, to the event-free survival curves. But thisshould result in an even more favorable picture of the chordal-cutting group, because there were only two patients in the chordal-cutting group that developed severe mitral regurgitation versus five in the undersized annuloplasty group. It is true that we did not reoperate on the two chordal-cutting patients who developed recurrent MR because they were very sick. However, four of the five undersized annuloplasty patients who developed recurrent MR underwent mitral valve replacement.

Dr. C. Duran (Missoula, MT):

One, we have to congratulate the authors for reporting on the only largest series with this intriguing very simple and, in my opinion, dangerous operation. I was also surprised, like Dr. Miller, that the center that has defended so clearly and as pioneers of this continuity between the papillary muscle and the annulus, now you recommend cutting the basal chords. You say they are different from the marginal chords. They certainly are very different in terms that they are four times the thickness of the marginal ones and they sustain stress during the whole cardiac cycle; they are taut during the whole cardiac cycle. So those very impressive chords when you look from the ventricle, to just cut them happily and hope that nothing happens I think is a bit premature.

We did repeat the studies, following closely the studies of the Stanford group, and in our case we cut the two medial anterior basal chords, that is, from both halves of the anterior leaflet, and the results immediately, those were acute experiments, there was a drop in stroke volume, $\mathrm{dP} / \mathrm{dt}$, increasing length between the apex and the annulus, and a reduction in the aortomitral angle. So they were all negative positions.

So my question is, why the difference, why your results are very good and the animal ones are very bad? Secondly, is that because in the animals we didn't do an annuloplasty and maybe the annuloplasty protects cutting those chords, or is it that we were cutting different chords than you were? And certainly from your presentation I get the idea that you cut the one from the A2 and commissure and the posterior leaflet at the level of B3. I don't know which, what explanation.

But before finishing, just a warning to people. The danger is it is a simple operation, but they just walk home and they say I am going 
to have a series of this new technique, and I think it would be premature. I think it is good for you to continue and to report what the long-term results are.

Thank you very much.

Dr. Borger: Thank you, Dr. Duran. I can see I am not gaining any friends with this operation. I want to stress one point. We are not trying to say that the chordal-cutting procedure is a panacea for ischemic mitral regurgitation. We have not found the cure for ischemic mitral regurgitation, by any means. I agree wholeheartedly with Dr. Miller and Dr. Gorman that this is a very vexing clinical problem and we don't have the answers yet, and surgery may not even be the best option for many of these patients. However, often you have patients that are hospitalized with congestive heart failure and surgery is the only potential life raft that they have.

Regarding the differences between our observations and the deleterious effects of cutting secondary chords in animal models, it is important to note that the animal models involve acute ischemic injury to normal ventricles. They are not chronic long-term ischemic ventricles like we see in patients. I believe that we should repeat the animal model work using hearts that have been ischemic for at least eight weeks before we definitively state that there are deleterious effects for this operation. It is also important to note that we have been dividing secondary chords during mitral valve repair for myxomatous disease for approximately 25 years, during the sliding annuloplasty procedure, without any obvious detrimental effects on left ventricular function.

And once again, I have to stress that we are not saying that we have found a cure for ischemic MR. We simply feel we have found a more effective method of decreasing the amount of residual and recurrent mitral regurgitation than the undersized annuloplasty procedure. As we continue to follow our patients, we hope to have some more answers for you over the next few years.

\section{JTCVS On-Line Manuscript Submission and Review}

The Journal of Thoracic and Cardiovascular Surgery requires authors and reviewers to submit all new and revised manuscripts and reviews via Editorial Manager. Point your browser to http://jtcvs.editorialmanager.com, log in as author or reviewer (as appropriate), and follow the instructions provided.

To retrieve your username and password, click "Forget your password?" on the Editorial Manager log-in page.

If you have questions or experience problems uploading your manuscript or review, please contact the editorial office:

Telephone: 215-762-1854

E-mail: jtcvs@drexelmed.edu 


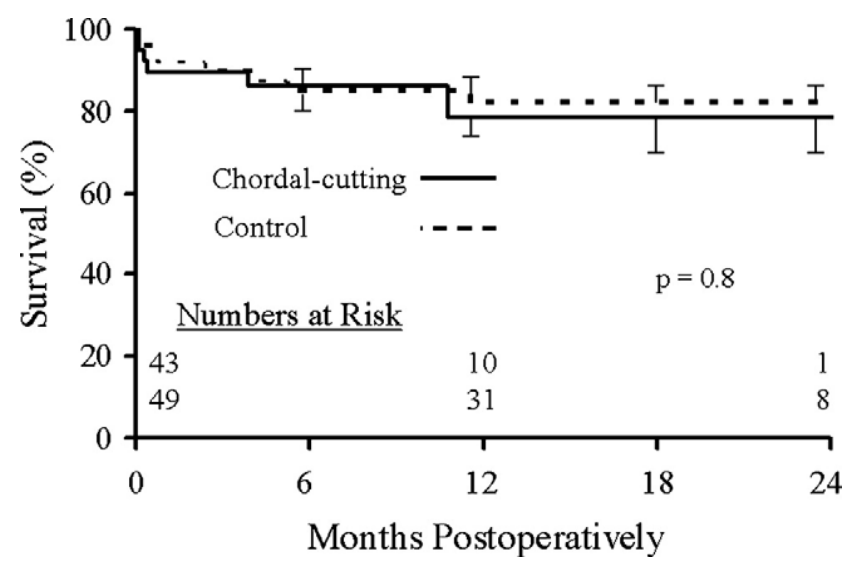

Figure E1. Survival ( \pm SEM) after MV repair for IMR in patients undergoing annuloplasty alone (control) versus annuloplasty plus division of secondary chords (chordal cutting). MV, Mitral valve; IMR, ischemic mitral regurgitation.

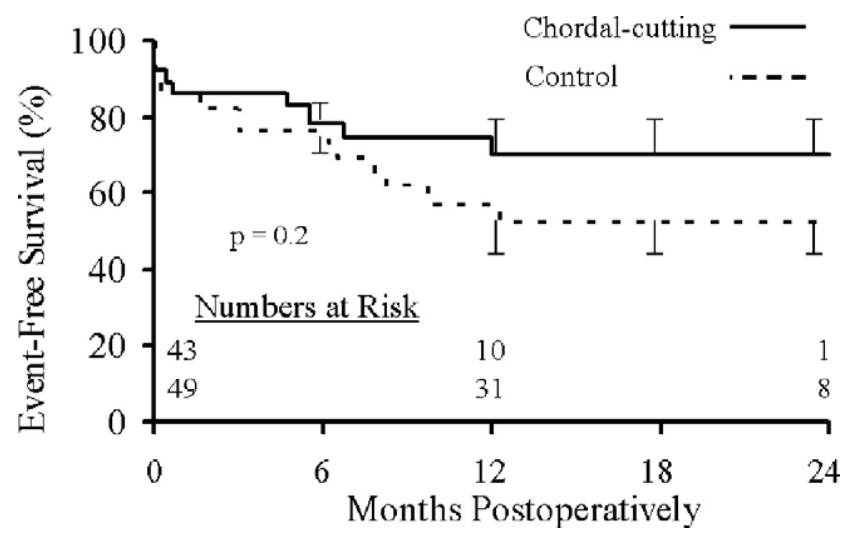

Figure E2. Event-free survival ( $(S E M)$ in patients undergoing annuloplasty alone (control) versus annuloplasty plus division of secondary chords (chordal cutting). Event-free survival was defined as freedom from death, recurrent moderate or more MR, reoperation, thromboembolism, hemolysis, major hemorrhage, or endocarditis. $M R$, mitral regurgitation. 